\title{
Micron-scale mapping of sulfur cycling across the oxycline of a cyanobacterial mat: a paired nanoSIMS and CARD-FISH approach
}

David Andrew Fike ${ }^{1}$, Crystal Lynn Gammon ${ }^{1}$, Wiebke Ziebis ${ }^{2}$ and Victoria Jeanne Orphan ${ }^{1}$ ${ }^{1}$ Division of Geological and Planetary Sciences, California Institute of Technology, Pasadena, CA, USA and

${ }^{2}$ Department of Biological Sciences, University of Southern California, Los Angeles, CA, USA

\begin{abstract}
The metabolic activities of microbial mats have likely regulated biogeochemical cycling over most of Earth's history. However, the relationship between metabolic activity and the establishment of isotopic geochemical gradients in these mats remains poorly constrained. Here we present a parallel microgeochemical and microbiological study of micron-scale sulfur cycling within hypersaline microbial mats from Guerrero Negro, Baja California Sur, Mexico. Dissolved sulfide within the mats was captured on silver discs and analyzed for its abundance and $\delta^{34} S$ isotopic composition using high-resolution secondary ion mass spectrometry (nanoSIMS). These results were compared to sulfide and oxygen microelectrode profiles. Two-dimensional microgeochemical mapping revealed well-defined laminations in sulfide concentration (on scales from 1 to $200 \mu \mathrm{m}$ ), trending toward increased sulfide concentrations at depth. Sulfide $\delta^{34} S$ decreased from $\sim+10 \%$ to $-20 \%$ in the uppermost $3 \mathrm{~mm}$ and oscillated repeatedly between $-10 \%$ and $-30 \%$ down to a depth of $8 \mathrm{~mm}$. These variations are attributed to spatially variable bacterial sulfate reduction within the mat. A parallel examination of the spatial distribution of known sulfate-reducing bacteria within the family Desulfobacteraceae was conducted using catalyzed reporter deposition fluorescence in situ hybridization. Significant concentrations of Desulfobacteraceae were observed in both oxic and anoxic zones of the mat and occurred in several distinct layers, in large aggregates and heterogeneously dispersed as single cells throughout. The spatial distribution of these microorganisms is consistent with the variation in sulfide concentration and isotopic composition we observed. The parallel application of the methodologies developed here can shed light on micronscale sulfur cycling within microbially dominated sedimentary environments.
\end{abstract}

The ISME Journal (2008) 2, 749-759; doi:10.1038/ismej.2008.39; published online 5 June 2008

Subject Category: geomicrobiology and microbial contributions to geochemical cycles

Keywords: Guerrero Negro; in situ hybridization; Microcoleus; nanoSIMS; sulfate-reducing bacteria; sulfur isotopes

\section{Introduction}

Microbial mats consist of finely laminated layers of phylogenetically and metabolically diverse microbial communities. Throughout most of Earth's history, the metabolic activity of such mats likely dominated biogeochemical cycling, impacting nutrient and oxygen availability (Hoehler et al., 2001; Anbar and Knoll, 2002; Hayes and Waldbauer, 2006). The abundance of microbially laminated

Correspondence: Victoria J Orphan or DA Fike, Division of Geological and Planetary Sciences, California Institute of Technology, MC 100-23, 1200 E. California Blvd., Pasadena, CA 91125, USA.

E-mails: vorphan@gps.caltech.edu or dfike@gps.caltech.edu

Received 10 January 2008; revised 17 March 2008; accepted 18 March 2008; published online 5 June 2008 sedimentary strata attests to the ubiquity of such mats and highlights their potential to preserve biosignatures over geologic time (Grotzinger and Knoll, 1999). Although the laminated architecture of microbial mats is thought to result from strong spatial gradients in light intensity and redox in their uppermost few millimeters, there is evidence for ongoing, localized metabolic activity at depth (Visscher et al., 2000; Dupraz et al., 2004; Wieland et al., 2005). Despite many decades of investigation, the relationship between microbial activity (on the micron scale) and the resulting isotopic geochemical profiles remains poorly understood. A refined understanding of how these are linked will improve our ability to understand modern biogeochemical cycling and to interpret the biological significance of geochemical patterns in the rock record. 
We have focused our study on sulfur cycling, in particular sulfate reduction, one of the dominant metabolisms within microbial mats (Canfield and Des Marais, 1993; Teske et al., 1998; Baumgartner et al., 2006). Mat-associated sulfate-reducing bacteria (SRB) were initially considered to be strict anaerobes residing below the oxic/anoxic chemocline, which was inhabited by sulfide oxidizers and presumably sulfur disproportionators that catabolize intermediate valence compounds $\left(\mathrm{S}^{0}, \mathrm{~S}_{2} \mathrm{O}_{3}^{2-}\right.$, $\mathrm{SO}_{3}^{2-}$ ) (Habicht et al., 1998). The discovery of abundant SRB and elevated sulfate-reduction rates in the oxic surface layers of mats indicates a more complicated spatial organization of the different sulfur-cycling metabolisms (Frund and Cohen, 1992; Canfield and Des Marais, 1993; Krekeler et al., 1997; Minz et al., 1999a; Sigalevich et al., 2000; Wieringa et al., 2000; Baumgartner et al., 2006). Indeed, among SRB, there is evidence for vertical segregation between different phylogenetic clades in microbial mats (Risatti et al., 1994; Minz et al., 1999b; Decho et al., 2005; Wieland et al., 2005). However, standard geochemical and microbiological techniques lack the spatial resolution to fully document the degree of SRB segregation and its biogeochemical consequences (Risatti et al., 1994), particularly given that lateral variability within these environments often makes one-dimensional (1D) depth studies problematic (Frund and Cohen, 1992).

The ideal geochemical tool for characterizing sulfur cycling in these environments would be able to determine not only the abundance but also the (natural) isotopic composition of relevant sulfur species and their 2D spatial distribution. Isotopic data are essential for separating the different pathways of sulfur cycling (oxidation, reduction and disproportionation), as each of these can be associated with different isotopic fractionations (Habicht et al., 1998). Most importantly, isotopic records can be preserved over geological time, providing the means to relate modern systems to the rock record (Canfield and Teske, 1996; Canfield, 2001; Habicht et al., 2002; Kampschulte and Strauss, 2004; Hurtgen et al., 2005; Fike et al., 2006; Gill et al., 2007). Ideally, to understand the intricacies of microbial interactions involved in sulfur cycling, measurements of sulfur species' concentration and isotopic composition should be made on the spatial scale most relevant to microbial activity: that of the micron-sized microorganisms whose various metabolisms drive the sulfur cycle.

The aim of this study was to develop such a technique using high-resolution secondary ion mass spectrometry (nanoSIMS) to analyze sulfide, coupling high-spatial (submicron) resolution with the ability to simultaneously measure sulfide abundance and isotopic composition. We compared microelectrode and nanoSIMS-acquired microgeochemical data to the spatial distribution of SRB within these mats using catalyzed reporter deposition fluorescence in situ hybridization (CARD-FISH)
(Pernthaler et al., 2002). Together, these measurements constitute a paired microbiological and microgeochemical approach that can be applied to correlate the micron-scale variations in microbial community and metabolic structure with the variations in the abundance and isotopic composition of sulfide produced during microbial sulfur cycling.

In this study, we analyzed the well-characterized Microcoleus-dominated benthic microbial mat communities from Exportadora del Sal, SA salt works at Guerrero Negro, Baja California Sur, Mexico. Previous studies of these mats have characterized the bulk microbiological community structure (Risatti et al., 1994; Spear et al., 2003; Ley et al., 2006), large-scale sulfur cycling (Canfield and Des Marais, 1993; Jorgensen, 1994) and daily variations in response to the periodic redox forcing from photosynthesis (Jorgensen, 1994; Visscher et al., 2003; Decker et al., 2005). Microcoleus-dominated mats also support active sulfate reduction by aerotolerant sulfate reducers (Teske et al., 1998) in the photosynthetically active uppermost few millimeters (Canfield and Des Marais, 1993). Analyses in the present study focused on the region around the oxic/ anoxic chemocline ( $\sim 2 \mathrm{~mm}$ depth during the day) to understand the changes in sulfur cycling that occur at and across this important geochemical and biological transition zone.

\section{Materials and methods}

Site description and sample collection

Push core samples of laminated Microcoleus mats ( 4- to 5-cm thick, see Supplementary Figure S1) were collected in April 2006 from a hypersaline pond (salinity of $\sim 90$ p.p.t.), known as pond 4 near 5 (P4n5), associated with Exportadora De Sal, SA in Guerrero Negro, Baja California Sur, Mexico. These hypersaline mats are characterized by high levels of sulfate $(\sim 80 \mathrm{mM})$ throughout the mat and in the overlying water. P4n5 mats are permanently submerged in approximately $1 \mathrm{~m}$ of pond water with a seasonal in situ temperature ranging from 14 to $29^{\circ} \mathrm{C}$. A detailed description of the area and mat geochemistry is provided in Des Marais et al. (1989) and Hoehler et al. (2001).

Cores consisting of mat and underlying sediment were transported back to the laboratory and maintained in a tank filled with water from pond 4 . Silver-disc incubations and microelectrode measurements were conducted in the laboratory on mats maintained within the core liner (overlain with approximately $6-7 \mathrm{~cm}$ of pond water).

\section{Microelectrode profiles of oxygen, hydrogen sulfide and $\mathrm{pH}$}

Vertical profiles of oxygen, hydrogen sulfide and $\mathrm{pH}$ were measured in intact mat cores under light exposure using microelectrodes (Unisense, 
Aarhaus, Denmark). The oxygen sensor was a Clark-type amperometric electrode with a built-in reference and a guard cathode (Unisense OX10; Revsbech, 1989) with a tip diameter of $20 \mu \mathrm{m}$, a stirring sensitivity of $<1 \%$ and a $90 \%$ response time $\leqslant 1 \mathrm{~s}$. The electrode currents have a linear response to oxygen dissolved in water. A two-point calibration was performed by inserting the oxygen electrode into a calibration chamber filled with water from the sampling site, which was purged with air $(100 \%$ saturation) or nitrogen ( $0 \%$ saturation) at the in situ temperature. The $\mathrm{H}_{2} \mathrm{~S}$ microsensor used in the analysis was a miniaturized amperometric sensor with an internal reference and a guard electrode (Unisense $\mathrm{H}_{2} \mathrm{~S} 25$; Jeroschewsky et al., 1996; Kuehl et al., 1998). The sensor had a long $(5 \mathrm{~cm})$ tapered tip with a tip diameter of $20 \mu \mathrm{m}$. The response time was $<2 \mathrm{~s}$. Total sulfide concentrations were calculated using $\mathrm{pH}$ values measured in tandem with the $\mathrm{H}_{2} \mathrm{~S}$ profiles using a $\mathrm{pH}$ microsensor ( $25 \mu \mathrm{m}$ tip diameter, Unisense pH25). Calibration of the $\mathrm{H}_{2} \mathrm{~S}$ microsensor was performed with anoxic $\mathrm{Na}_{2} \mathrm{~S}$ standards of known concentrations measured by colorimetric analysis (Cline, 1969). The $\mathrm{pH}$ electrode was calibrated using standard $\mathrm{pH}$ buffer solutions (VWR).

The electrodes were attached to a micromanipulator and moved vertically into the mat via a computer-controlled motor (Unisense MC18011). Amperometric sensors were connected to a highsensitivity picoammeter (Unisense PA2000) and the cathodes were polarized against an internal reference. The $\mathrm{pH}$ sensor was connected to a highimpedance $\mathrm{mV}$ meter (Unisense PHM210). Amperometric signals were amplified and transformed to $\mathrm{mV}$ by the picoammeter, and data were collected directly on a computer using the software Profix (Unisense). Measurements were performed in vertical increments of $100 \mu \mathrm{m}$ for oxygen and $200 \mu \mathrm{m}$ for $\mathrm{H}_{2} \mathrm{~S}$ and $\mathrm{pH}$. The position of the microsensor in relation to the mat-water interface ( 0 position) was determined visually using a dissecting microscope (Leica Microscope Systems AG, Wetzlar, Germany). Profiles were performed under full light exposure using a cold light source (McBain Instruments, Chatsworth, CA, USA), photon flux as a combination of ambient day light in the lab and direct exposure of the mat surface to the light source was measured as $270 \mu \mathrm{M} \mathrm{s}^{-1} \mathrm{~m}^{-2}$.

\section{Catalyzed reporter deposition fluorescence in situ hybridization}

Samples of mat to be used for fluorescence in situ hybridization were fixed with freshly prepared paraformaldehyde (4\%) and incubated for either $2 \mathrm{~h}$ at room temperature or overnight at $4{ }^{\circ} \mathrm{C}$. After fixation, mat samples were transferred into $1 \times$ phosphate-buffered saline (PBS) solution ( $\mathrm{pH}$ 8.0), incubated for $1 \mathrm{~h}$ at room temperature and washed another two times with PBS to remove traces of paraformaldehyde (Pernthaler et al., 2004). Washed samples were stored in a 1:1 (v/v) mixture of PBS and ethanol at $-20^{\circ} \mathrm{C}$. Whole mat sections were embedded in Steedman's wax (Steedman, 1957) and thin-sectioned into $10-\mu \mathrm{m}$ slices using a microtome (Leica Microscope Systems AG) according to Pernthaler et al. (2002). To compensate for the autofluorescence and high-background signal inherent in photosynthetic mats, a modified CARD-FISH signal-enhancement procedure was applied to visualize SRB populations. The final optimized protocol included dehydrating the mat sample in $100 \%$ ethanol ( $2 \mathrm{~min}$ ), followed by two separate incubation steps to inactivate endogeneous peroxidases: $10 \mathrm{~min}$ in $0.1 \mathrm{~N} \mathrm{HCl}$ and $30 \mathrm{~min}$ in $0.1 \%$ hydrogen peroxide (diluted from $30 \%$ with $1 \times$ PBS). Each of these incubations was followed by a second wash step in nanopure water and ethanol dehydration. To increase cell permeability, samples were incubated in TE buffer (10 mM Tris HCl; 1 mM EDTA, pH 9.0) for $3 \mathrm{~min}$ in a hybridization microwave oven (Microwave Research Applications Inc., Laurel, MD, USA) at $60{ }^{\circ} \mathrm{C}$ set at maximum power. The pre-conditioned mat sections were then washed in nanopure water and hybridized in $300 \mu \mathrm{l}$ of the CARD-FISH hybridization buffer containing $50 \%$ formamide and $1 \mu \mathrm{l}$ of $50 \mathrm{ng} \mu \mathrm{l}^{-1}$ horseradish peroxidase-labeled oligonucleotide probe (Biomers, Ulm, Germany) following the protocol of Pernthaler et al. (2004). Hybridizations were carried out in a sealed slide chamber in the hybridization microwave at $46{ }^{\circ} \mathrm{C}$ for $30 \mathrm{~min}$. A 15-min post-wash in PBS at room temperature followed the hybridization. Tyramide amplification was found to be optimal using a 1:1000 dilution of the fluorescein-tyramide (Invitrogen, Carlsbad, CA, USA). Amplification included a 15-min incubation at $37^{\circ} \mathrm{C}$. After fluorescent amplification, slides were washed in series using PBS (10 min), nanopure water $(2 \mathrm{~min})$ and ethanol (2 min), and then air-dried in the dark prior to viewing. The oligonucleotide probe used in this study was the Desulfobacteraceae-specific probe DSS658 (probebase accession no. pB-00084) (Loy et al., 2007). The probe contained no mismatches with 13 GenBank sequences and a single peripheral mismatch to two additional GenBank sequences previously recovered from the Guerrero Negro mats (Supplementary Table S1). Formamide gradients in increments of $5 \%$ were tested during the microwave CARD-FISH hybridization. The optimal formamide concentration was consistently found to be $10 \%$ lower in microwave hybridizations than in oven hybridizations for all probes tested. As such, a 50\% formamide concentration was used in the hybridization buffer rather than the $60 \%$ reported in Manz et al. (1998).

Slides were examined on a DeltaVision RT deconvolution microscope system (Applied Precision, Ithaca, WA, USA) with either a $\times 20, \times 40$ or $\times 60$ Olympus objective (PlanApo or UPlanApo). Images were captured and processed using Softworx 


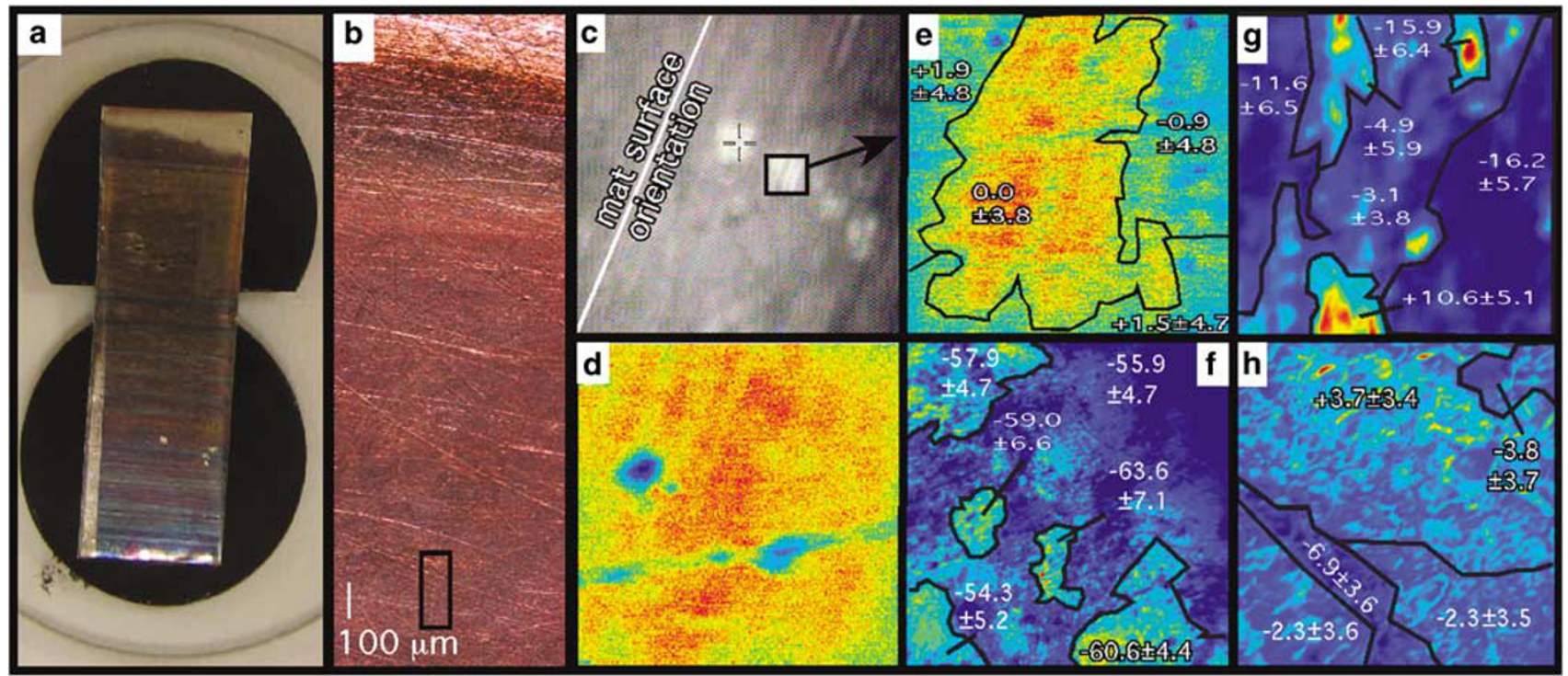

Figure 1 Sulfide laminations within microbial mats maintained in the laboratory. (a) Millimeter-scale banding visible on silver foil. Glass disc is $2.5 \mathrm{~cm}$. (b) Optical microscopic image of a silver disc. Bright material at top is metallic silver; brown is $\mathrm{Ag}_{2} \mathrm{~S}$. A transect of nanoSIMS spot analyses (white dots) is visible (boxed). Isotopic results from these points are seen in Figure 2. (c) NanoSIMS optical image showing collection of several ${ }^{32} \mathrm{~S}$ ion images $(6 \mu \mathrm{m} \times 6 \mu \mathrm{m})$. The box corresponds to the ion image in (e). Note parallel laminations in sulfide aligned with the mat surface orientation. $(\mathbf{d}-\mathbf{g})^{32} \mathrm{~S}$ images from mat incubations. (d, e, g) Fine-scale banding parallel to the mat surface, whereas (f) shows irregular patchiness. $(\mathbf{e}-\mathbf{g}) \delta^{34} S$ values overlain on top of their ${ }^{32} \mathrm{~S}$ images, mapping the isotopic composition of distinctive ${ }^{32} \mathrm{~S}$ regions. No significant deviation in $\delta^{34} S$ is observed in (e) and (f), whereas (g) has $\sim 25 \%$ variability in localized regions. (h) Image of the precipitated standard, showing small-scale irregularities in ${ }^{32} \mathrm{~S}$ and a $9 \%$ range in $\delta^{34} \mathrm{~S}$. Color scale for images are as follows (in ${ }^{32} \mathrm{~S}$ counts): (d) 0-236; (e) 0-577; (f) 0-7, 627; (g) 0-2, 116; (h) 0-26, 031.

package (version 3.5.1; Applied Precision) and exported as TIFFs for figure assembly in Adobe Photoshop CS (Adobe Systems Incorporated).

\section{Sulfide capture using silver discs}

Dissolved sulfide was captured as silver sulfide $\left(\mathrm{Ag}_{2} \mathrm{~S}\right)$ by incubating either silver foil (Figure 1a) or a metallic silver disc $(2.5 \mathrm{~cm}$ diameter $)$ in the microbial mat (see Supplementary Figure S1). This method is an adaptation of a technique previously used in ${ }^{35}$ S-radiolabel studies (Visscher et al., 2000; Dupraz et al., 2004; Wieland et al., 2005), where silver foil was coated with ${ }^{35} \mathrm{SO}_{4}$. After incubation, radiography of the precipitated silver sulfide documented the presence of any ${ }^{35} \mathrm{~S}$ in the silver sulfide, which was attributed to sulfate reduction during the incubation (Visscher et al., 2000). In contrast, the approach here does not involve the addition of any isotopic spike to the microbial mat and preserves the natural isotopic composition of sulfide in these systems. Precipitated sulfide is a combination of ambient sulfide present when the disc was inserted and that produced by biological sulfate reduction and subsequently diffused to the disc during the incubation.

Silver-disc incubations were conducted for $12 \mathrm{~h}$ on two different P4n5 mat cores under full illumination using a cold light source (McBain Instruments) providing a light intensity of $\sim 270 \mu \mathrm{M} \mathrm{s}^{-1} \mathrm{~m}^{-2}$. Upon exposure to light, signs of active photosynthesis were observed, including active oxygen production in the upper 1-2 mm (measured by microelectrode) and the formation of gas bubbles on the surface of the mat. The temperature during incubations was $\sim 23^{\circ} \mathrm{C}$. For mat no. 2, microelectrode measurements were acquired prior to disc incubations and samples for FISH microscopy were collected adjacent to the disc immediately following the incubation under full light exposure. In both mats, less than $\sim 1 \%$ of pore water sulfate was reduced, ensuring open system behavior (Habicht and Canfield, 1996).

Visible sulfide precipitation in both of these laboratory experiments first occurred approximately $0.4 \mathrm{~mm}$ below the mat surface with trace levels detectable above by the nanoSIMS. The top of this visible sulfide accumulation serves as the origin in Figures 2 and 3. Because of mat-surface irregularities (see Figure 4), there was some uncertainty in the absolute distance between the tops of the sulfide layer and the local mat surface.

\section{NanoSIMS analysis and isotopic calibration}

The Cameca nanoSIMS 50L is a high-resolution secondary ion mass spectrometer that can collect up to seven ions simultaneously and operate in either cesium ion or oxygen ion mode. The nanoSIMS has previously been used to analyze sulfur isotopes in minerals (Slodzian et al., 2004; Hoppe et al., 2005) and carbon, nitrogen and sulfur distributions in 
biological samples (Clode et al., 2007; Li et al., 2008). For the present study, data were obtained using electron multiplier multi-collection, operating with the cesium $\left(\mathrm{Cs}^{+}\right)$ion source. An $\sim 40-$ pA beam was used and the sample surface was pre-sputtered for $120 \mathrm{~s}$ prior to analysis. Data were typically

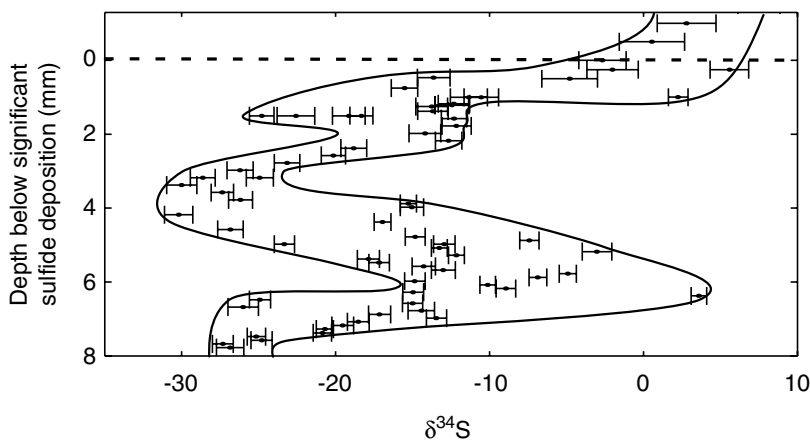

Figure 2 Example of $\delta^{34} \mathrm{~S}$ profile with depth through the mat. The origin is set to the first visible layer of sulfide at $\sim 0.4 \mathrm{~mm}$ below the mat surface.

a

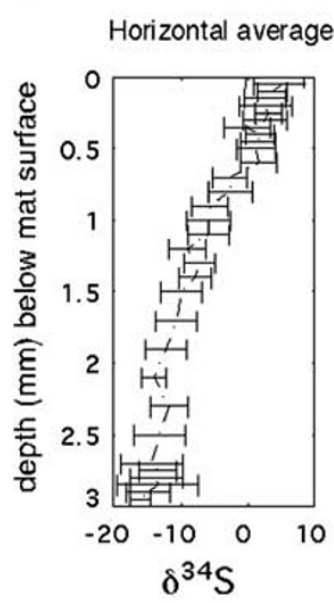

c

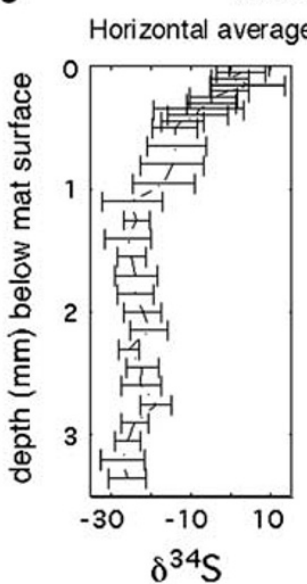

Mat \#1 $\delta^{34}$ S composition
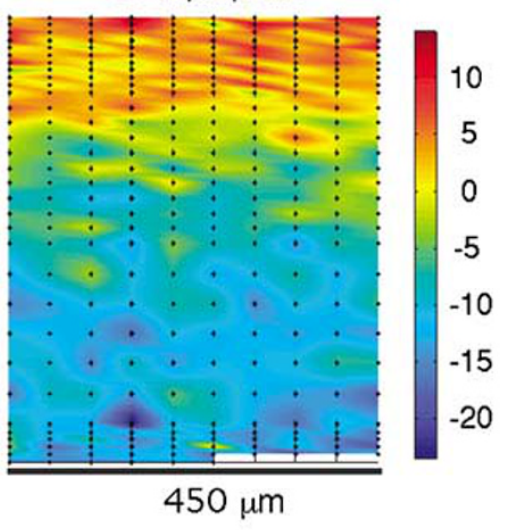
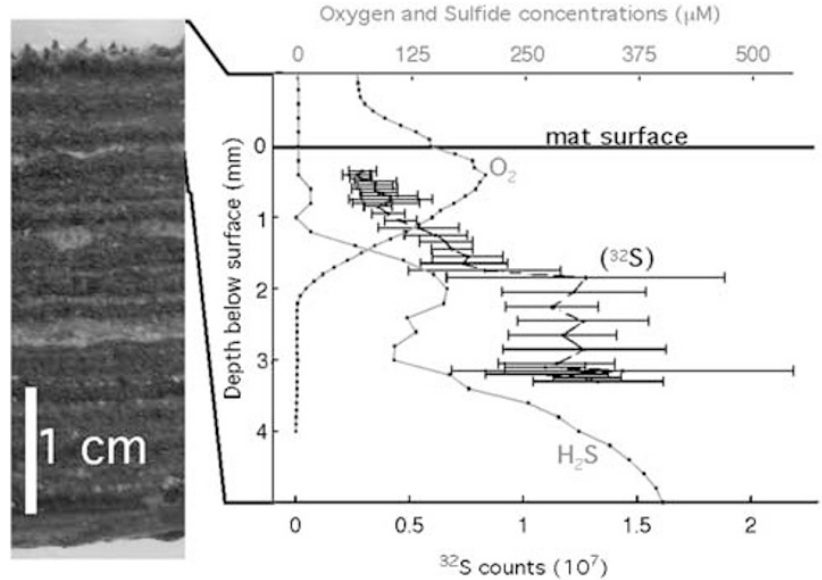

Figure 4 Image of Microcoleus-dominated subtidal microbial mat from Guerrero Negro (left panel). Note irregularities in mat surface and laminated structure. Microelectrode depth profiles on the right $\left(\mathrm{O}_{2}\right.$ and $\left.\mathrm{H}_{2} \mathrm{~S}\right)$, alongside nanoSIMS ${ }^{32} \mathrm{~S}$ counts of sulfide precipitated on the silver disc during incubation under active photosynthesis. Error bars for ${ }^{32} \mathrm{~S}$ counts represent the standard deviation from adjacent parallel sections $(n=10)$.

b Mat \#1 ${ }^{32} \mathrm{~S}$ abundance
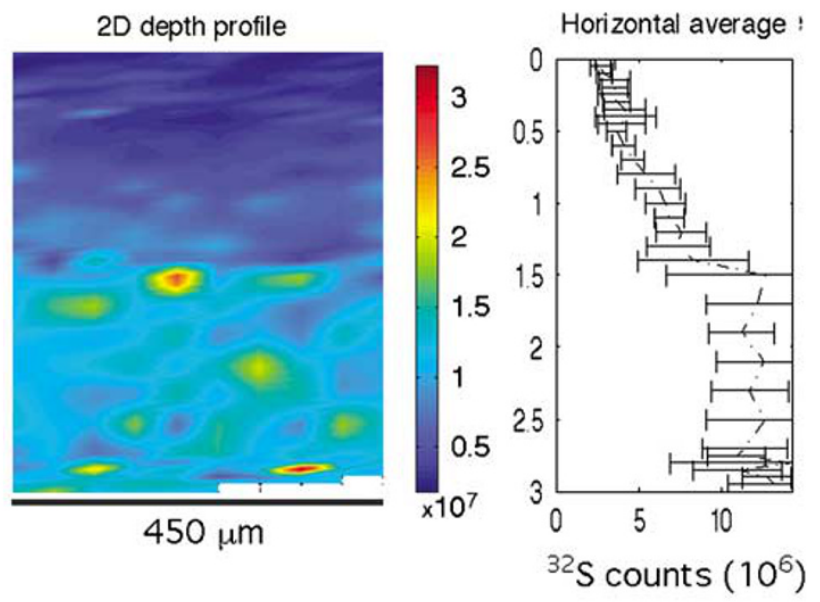

d

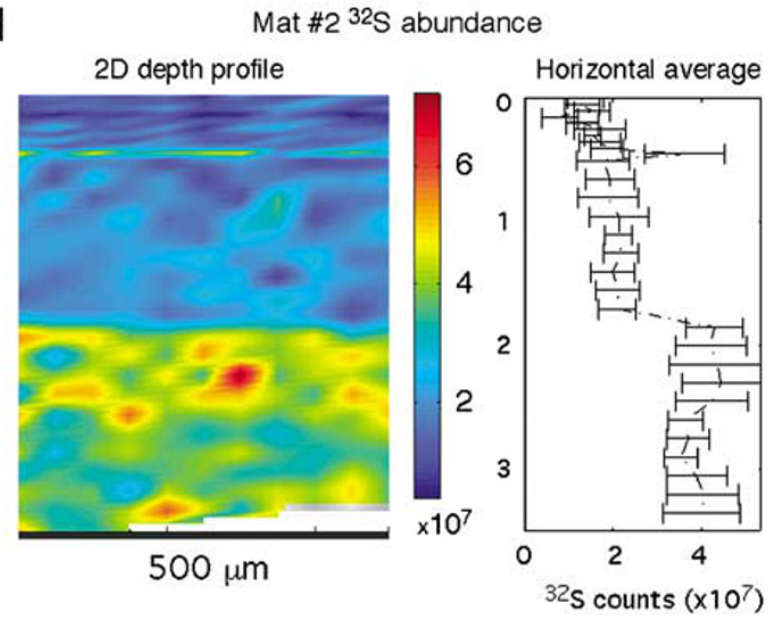

Figure 3 Plot of $\delta^{34} S$ and ${ }^{32} S$ for two different incubation experiments (12 h during the day). Lateral distance is $450 \mu \mathrm{m}$ in (a) and (b) and $500 \mu \mathrm{m}$ in (c) and (d). Black dots on (a) and (c) indicate sampling frequency. Plot was made using linear interpolation between measured points. Error bars on averages indicate the standard deviation for measurements for a given depth. 
collected for $1000 \mathrm{~s} .{ }^{32} \mathrm{~S}$ and ${ }^{34} \mathrm{~S}$ ions were measured simultaneously. This provides a means to calculate $\delta^{34} \mathrm{~S}=\left(R_{\text {sample }} / R_{\text {standard }}-1\right) \times 1000$, reported in permil (\%) relative to the international Vienna Canyon Diablo Troilite standard, where $R$ is the ${ }^{34} \mathrm{~S} /{ }^{32} \mathrm{~S}$ ratio. Reference $\delta^{34} \mathrm{~S}$ values for P4n5 sulfate were obtained by elemental analyzer-isotope ratio mass spectrometry analysis of $\mathrm{BaSO}_{4}$ precipitated from P4n5 water by the addition of a saturated $\mathrm{BaCl}_{2}$ solution.

Instrument mass fractionation was corrected by calibration to silver sulfides of known isotopic composition (Supplementary Figure S2). Two forms of standards were used: acanthite $\left(\mathrm{Ag}_{2} \mathrm{~S}\right)$ mineral standards and precipitated silver sulfide. For nanoSIMS analysis, acanthite minerals were subsampled and embedded in epoxy and polished, whereas silver sulfide was precipitated onto silver discs by the addition of $\mathrm{AgNO}_{3}$ to a dissolved sulfide solution ( $10 \mathrm{mM} \mathrm{Na} \mathrm{ma}_{2} \mathrm{~S}$ ) of known isotopic composition ('precipitated standard'). For conventional analysis, another aliquot of sulfide solution was precipitated with $\mathrm{AgNO}_{3}$. The resulting silver sulfide precipitate was powdered, along with acanthite minerals. These samples were combined with excess $\mathrm{V}_{2} \mathrm{O}_{5}$ and combusted to $\mathrm{SO}_{2}$ and analyzed conventionally for $\delta^{34} S$ using elemental analyzer-isotope ratio mass spectrometry (Studley et al., 2002). Standard deviations $(1 \sigma)$ were $0.1 \%$ for known standards and precipitated silver sulfide, and $\sim 1 \%$ for acanthite minerals, presumably due to inhomogeneities between subsampled crystals.

The analytic precision of the nanoSIMS for $\delta^{34} S$ analysis on sulfide mineral standards ranged between $0.4 \%$ and $0.8 \%$ based on Poisson counting statistics with an internal standard error of $0.5 \%$ $1.0 \%$. The standard deviation (external precision)

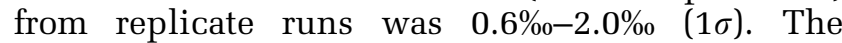
analytic precision for the precipitated standards was $0.4 \%$ based on Poisson counting statistics with an internal standard error of $0.4 \%{ }_{0}-0.6 \%$. However, the external precision of the precipitated standards was $\sim 3.5 \%(1 \sigma)$, which likely reflects both the limited abundance of silver sulfide on the disc surface, small topographic irregularities and heterogeneous deposition rates. This method is less precise than measuring bulk homogeneous crystals (that is, acanthite), but sufficient to resolve the $>10 \%$ variations in sulfide $\delta^{34} S$ that typically characterize microbial systems (Habicht et al., 1998).

The nanoSIMS beam ionized a considerable fraction of the silver sulfide during analysis of both precipitated standards and mat incubations (Figures $1 \mathrm{~b}$ and $\mathrm{c}$ ). Thus, for each measurement, the total sulfur yield decreased with time (see Supplemental Figure S3), precluding a steady-state counting rate for the secondary ion beam, as is routinely achieved for analysis of mineral specimens. However, there was no observed temporal trend in the isotope ratio of sulfide (Supplemental Figure S3), strongly suggesting that the decreasing yield did not cause an isotopic offset in the data. The nanoSIMS-generated data set was also examined for evidence of a quasisimultaneous arrival (QSA) effect, which has been suggested to generate isotopic fractionations during sulfur isotope (and other) measurements made using electron multipliers on the nanoSIMS (Slodzian et al., 2004). Operating conditions $(\mathrm{K}<0.0025)$ indicate that any correction would have been minimal $(<2 \%)$, and no evidence for this effect was observed in analysis of $>300$ data points. As such, no correction was applied (see Supplementary text and Supplemental Figure S4).

\section{Results}

Ion images of captured sulfide from the mats Data were collected using a Cameca nanoSIMS 50L in both 'image' and 'spot' mode on silver discs incubated in the microbial mats. In image mode, the beam was rastered over a $6 \mu \mathrm{m} \times 6 \mu \mathrm{m}$ square (typically $256 \times 256$ pixels). The sulfur ion images collected in this manner from mat incubations preserve ultra-high resolution spatial variability that reveals laminations and patchiness in sulfide abundance on the micron-scale (Figures 1d-g), which differ in appearance from the precipitated standard (Figure 1h). The measured sulfur isotopic composition of the mat ion-image analyses ranged between $+11 \%$ and $-64 \%$. In two of the images (Figures $1 \mathrm{e}$ and $\mathrm{f}$ ), there was no significant variability in $\delta^{34} \mathrm{~S}$ within the image, particularly between regions of high and low sulfide abundance, whereas in Figure $1 \mathrm{~g}$, variability up to $\sim 25 \%$ was observed between some adjacent regions with no variability between others. In comparison, the precipitated standard had a $9 \%$ range in $\delta^{34} S$ (Figure 1h). One of the difficulties in analyzing isotopic compositions of materials at this scale is the challenge of procuring standards that are isotopically homogenous on the submicron scale. Figure $1 \mathrm{~h}$ demonstrates that our precipitated standard is not isotopically homogenous on the smallest scale we can examine. As such, errors reported here for image analyses (Figure 1) combine the error of the individual image analyses based on Poisson counting statistics, with the estimated $3.5 \%$ orror associated with precipitation on the sulfide disc (see above). In the absence of an isotopically homogenous standard at this spatial resolution, these errors should be considered as an approximation of the true error.

Spot analyses of captured sulfide from the mats

NanoSIMS data were also collected using the instrument in spot mode, rastering the beam over a $6 \mu \mathrm{m} \times 6 \mu \mathrm{m}$ area and spatially integrating the resulting data for increased isotopic precision (at the cost of spatial resolution finer than the spot size). Collection of spot measurements allows for the generation of $1 \mathrm{D}$ depth profiles in $\delta^{34} \mathrm{~S}$. At a spatial 
resolution of $\sim 50-100 \mu \mathrm{m}$, coherent trends in $\delta^{34} \mathrm{~S}$ are apparent with depth (Figure 2). Enriched $\delta^{34} S$ values $(\sim+5 \%)$ characterized the uppermost sulfide zone associated with the photosynthetically active depth horizon. With increasing depth in the mat, sulfide $\delta^{34} S$ dropped rapidly to $-25 \%$ over $2 \mathrm{~mm}$ and coherent variations of up to $30 \%$ were observed down to a depth of $8 \mathrm{~mm}$ (Figure 2). Given a bulk starting sulfate composition of $+20 \%$, these data correspond to sulfate-sulfide fractionations of $15 \% 0-55 \%$.

The collection of $2 \mathrm{D}$ depth profiles provides a window into lateral, as well as vertical, variability in mat sulfur cycling (Figure 3). Here, spot measurements were collected every $\sim 50-200 \mu \mathrm{m}$ to generate millimeter-scale 2D maps of sulfide concentration and $\delta^{34} \mathrm{~S}$ isotopic composition through two different mats incubated during active photosynthesis. The first-order trend in both incubations was increased sulfide abundance with depth (Figure 3), consistent with microelectrode profiles in these mats (Figure 4) and in similar mat environments (Jorgensen et al., 1979; Revsbech et al., 1983; Canfield and Des Marais, 1993). Superimposed on this trend, several $\sim 50$ - to $400-\mu \mathrm{m}$ thick horizontal laminations in sulfide abundance were observed, as well as similarly sized, localized zones of variable sulfide concentration. In particular, a well-defined band ( $\sim 100-\mu \mathrm{m}$ thick) of increased sulfide abundance was found at a depth of $0.5 \mathrm{~mm}$ in mat no. 2 (Figure 3d), within the oxic zone of the mat (Figure 4). Resolution of more closely spaced laminations (as in Figure 1) was not possible when collecting data over such a (relatively) large area. However, given the banding observed in the ion images from Figure 1, the scale of variations in sulfide abundance likely spans the range of 1$400 \mu \mathrm{m}$. The combination of laminated and irregular variability in sulfide abundance matches with the spatial patterns of sulfate-reduction rates reported previously in microbial mats and stromatolites (Visscher et al., 2000; Wieland et al., 2005).

The isotopic composition of sulfide also displayed coherent trends with depth in both incubations, decreasing by $30 \% 0-40 \%$ in the upper $3 \mathrm{~mm}$ (Figure 3 ). $\delta^{34} S$ values just below the mat surface were typically enriched $(0 \%-10 \%)$, corresponding to a relatively small fractionation between sulfate and sulfide (10\%o-20\%). Sulfide $\delta^{34} \mathrm{~S}$ decreased with depth to $\sim-20 \%$ over $1-2 \mathrm{~mm}$, approaching the lower end of the periodically aerobic portion of the mat (Figure 4). Although sulfide abundance increased sharply in both incubations at $\sim 1.5 \mathrm{~mm}$, $\delta^{34} S$ increased in mat no. 1 gradually with depth until about $2 \mathrm{~mm}$, whereas $\delta^{34} \mathrm{~S}$ increased in mat no. 2 until $\sim 1 \mathrm{~mm}$, after which it did not vary significantly. At all depths, horizontal and vertical variation in $\delta^{34} S$ of $\sim 10 \%$ was found at the scale of $\sim 50 \mu \mathrm{m}$ (Figure 3). A similar scale of spatial variability in $\delta^{34} S$ and sulfide abundance was observed. The isotopic variability in these spot analyses (Figures 2 and 3) reflects fractionations between sulfate and sulfide of $5 \%-55 \%$.

The nanoSIMS spot analysis of mat sulfide $\delta^{34} \mathrm{~S}$ values range between $+15 \%$ and $-35 \%$ with the greatest variability in the upper $0-2 \mathrm{~mm}$ of the mat. The majority of this variability occurs in the upper millimeter of mat, where sulfide concentrations are lowest. The average value of sulfide from below this zone (that is, where most of the sulfide occurs) is $-23.5 \% \pm 4.8 \%(n=157)$. This value agrees with bulk mat $\delta^{34} S(-26.8 \%)$ as determined by elemental analyzer-isotope ratio mass spectrometry by precipitating sulfide from the upper $5 \mathrm{~cm}$ of the P4n5 mat with excess $\mathrm{AgNO}_{3}$ (Supplemental Figure S2). These values are also in agreement with the known variability of sulfide $(-19 \%$ to $-27 \%)$ in the mats from Guerrero Negro (B Thamdrup and S Severmann, unpublished data).

\section{SRB spatial distribution}

Previous work has shown that sulfur-cycling organisms form a major metabolic and phylogenetic component of microbial mats in Guerrero Negro and similar environments (Canfield and Des Marais, 1993; Jorgensen, 1994; Risatti et al., 1994; Krekeler et al., 1997; Teske et al., 1998; Minz et al., 1999a,b; Spear et al., 2003; Sorensen et al., 2005; Ley et al., 2006). Whole-cell FISH surveys of microbial assemblages within the mat, focusing on sulfate reducers and other known monophyletic sulfur-metabolizing guilds, allow for micron-scale mapping of the spatial distribution of these organisms (for example, Minz et al., 1999a; Wieland et al., 2003; Tonolla et al., 2005; Baumgartner et al., 2006). The spatial relationships of mat-associated SRB populations (Figure 5) have not been previously reported within these highly structured microbial communities at this resolution and continuous physical extent $\left(>12 \mathrm{~mm}^{2}\right)$.

In this study, horseradish peroxidase-labeled CARD-FISH probes were used to target SRB in the Guerrero Negro microbial mats. Samples for FISH were collected directly adjacent to the disc-incubation sites and sampled at the same point in the diel cycle. The oligonucleotide probe DSS658 (Manz et al., 1998) targets several genera within the Desulfobacteraceae family, including Desulfosarcina, Desulfococcus and Desulfonema (92\%, 82\% and $19 \%$ coverage of each genus, respectively; see Supplementary Table S1). SRB targeted by the DSS658 probe were found throughout the mat, concentrated in continuous bands within the top $\sim 2 \mathrm{~mm}$ (oxic portion) of the mat immediately adjacent to a dense layer of phototrophs (indicated by red autofluorescence) and in more dispersed, though still continuous, layers below the chemocline to a depth greater than $3.5 \mathrm{~mm}$ (Figure 5a). These SRB bands appeared to be laterally continuous for at least $4 \mathrm{~mm}$. There was a distinct change in morphology from bands dominated by cocci in 

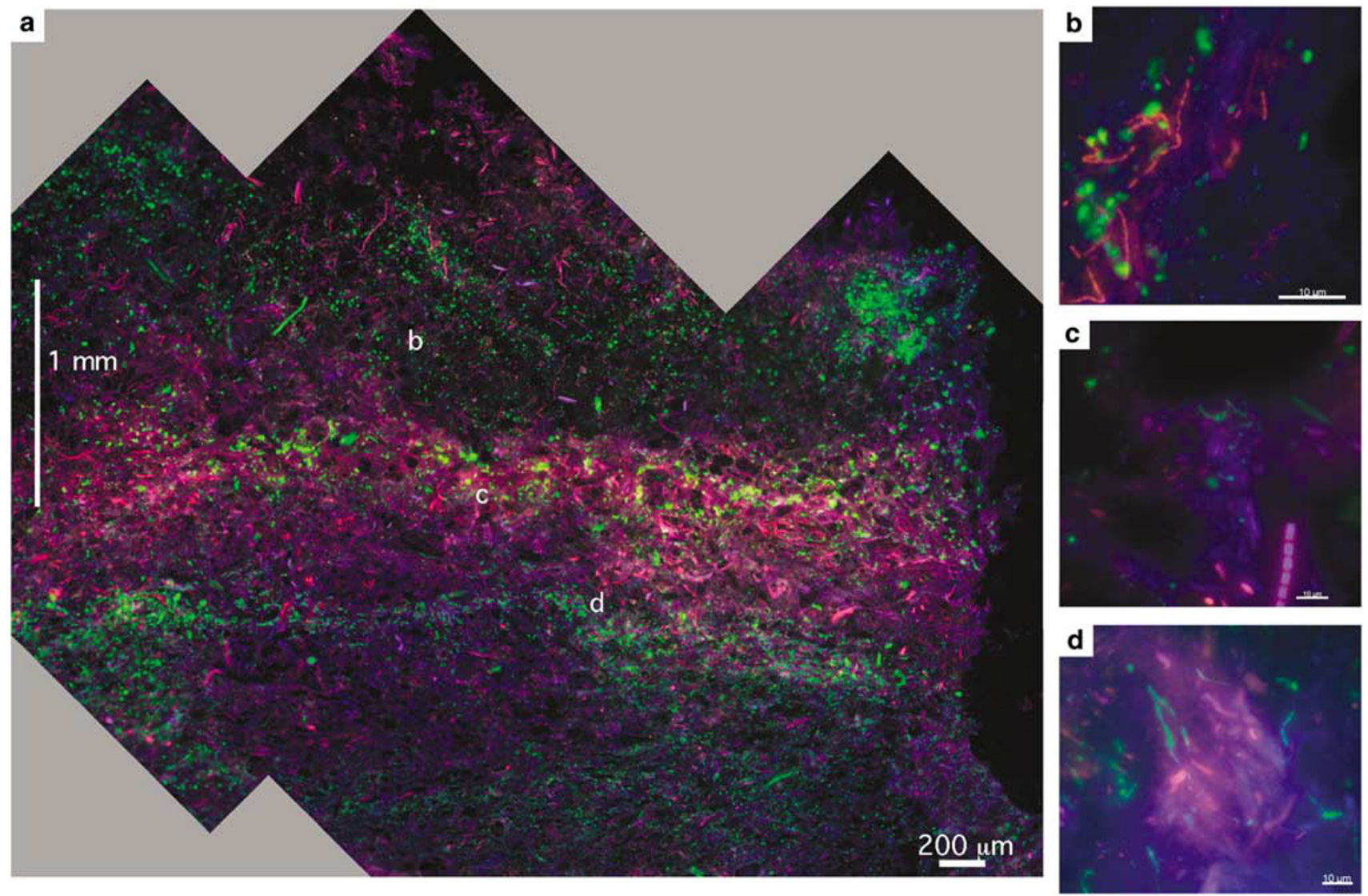

Figure 5 Epifluorescence microscopy image of Guerrero Negro mat thin section hybridized with the Desulfobacteraceae-specific probe, DSS658. (a) Composite low-magnification $(\times 20)$ image. For all panels: DSS 658 probe (green); DAPI, a general DNA stain (blue); and photopigment autofluorescence (red) indicating the presence of phototrophs. Note, cyanobacteria appear magenta because of an overlay of DAPI staining and autofluorescence. (b-d) High-magnification $(\times 60)$ images; scale bar is $10 \mu \mathrm{m}$. (b) Coccoid SRBs in zone b (refer to (a)); note proximity to photosynthesizing filaments. (c) Coccoid and filamentous SRBs in zone c. A large Microcoleous filament, the major mat-forming population in the mats, can be seen at the bottom right. (d) Filamentous SRB in zone d. Note the change in SRB morphology throughout the (b-d) transect. DAPI, 4'-6-diamidino-2-phenylindole; SRB, sulfate-reducing bacteria.

the uppermost $\sim 1 \mathrm{~mm}$ to filament-dominated bands located below the photic zone (Figures 5b-d). Aggregates of Desulfobacteraceae between 20 and $500 \mu \mathrm{m}$ in size were also observed in the upper portion of the mat (Figure 5a). These observed spatial trends were consistent throughout repeated hybridization experiments on multiple mat thin sections.

\section{Discussion}

Cycling of sulfur within microbially dominated sedimentary systems is complex and is controlled by a combination of both biological and physicochemical factors. For example, the observed finescale laminations in sulfide concentration (Figure 1) could arise from different rates of active sulfate reduction (production) and/or differential diffusion of sulfide through mat layers (transport). The laminations within microbial mats are known to possess different diffusivities (Wieland et al., 2001) and this is likely to contribute in some extent to the variations in sulfide abundance. However, our preliminary observations indicate that the amount of sulfide precipitated on the silver surface (as total ${ }^{32} \mathrm{~S}$ counts on the nanoSIMS) was proportional to total sulfide as measured by microelectrodes (Figure 4). The horizontal and vertical variabilities in the isotopic composition of sulfide over short distances (20\% over $\sim 2 \mathrm{~mm}$ ) are inconsistent with fractionations resulting from purely differential diffusion and argue for localized bacterial-sulfate reduction and/or other sulfur metabolisms at depth.

Mat-surface irregularity and lateral heterogeneity prevent direct comparison between the distribution of microbial assemblages visualized by CARD-FISH and nanoSIMS data collected immediately adjacent within the mat. However, visual observations indicate that the spacing and thickness of the SRB bands are consistent with the laminations in sulfide abundance and its isotope composition (Figures $1-3)$. The genera targeted by the DSS658 probe have been shown to comprise a large proportion of SRB within these mats (Risatti et al., 1994; Minz et al., 1999a) and have been found to contribute to sulfate reduction in a variety of oxic and suboxic environments (Cypionka, 2000). Thus, it is likely that these 
dense bands of Desulfobacteraceae are in part responsible for many of the macro-scale trends in sulfide deposition on the silver foil. Minz et al. (1999a) noted remarkably similar spatial distributions in Desulfobacteraceae-associated rRNA in the oxycline of a microbial mat from Solar Lake, Egypt using rRNA blot hybridizations at $100-\mu \mathrm{m}$ depth intervals, suggesting this may be a ubiquitous phenomenon.

In addition to laminated structures, there were zones of variable ('patchy') sulfide abundance and isotopic composition on the scale between 1 and $400 \mu \mathrm{m}$, which suggest heterogeneous sulfate reduction (Figures 1-3). Many of the Desulfobacteraceaeaffiliated microorganisms in Figure 5 have a filamentous morphology analogous to members of the Desulfonema, an aerotolerant SRB common within the mat environment (Teske et al., 1998). SRB are also found in aggregates with similar scale and spatial distribution as that apparent in the nanoSIMS data (Figures 1 and 3). This observed clumping of SRB, particularly in the oxic zone (Figure 5a), has been reported from other oxic habitats, and is thought to generate microenvironments that favor continued sulfate reduction (Cypionka, 2000; Sigalevich et al., 2000; Wieland et al., 2005). The occurrence of SRB in oxic zones may be a trade-off between oxygen stress and the proximity to photosynthate that can be used during sulfate reduction (Frund and Cohen, 1992; Wieland et al., 2005). Both SRB populations and organic substrate consumption are known to vary with depth, supporting spatially variable sulfate reduction based upon the flow of energy and organic carbon substrates (Frund and Cohen, 1992; Risatti et al., 1994; Sigalevich et al., 2000; Wieland et al., 2005; Musselwhite et al., 2007). Such heterogeneous sulfate reduction naturally explains the patchiness in sulfide abundance and isotopic composition observed in this study.

The fractionations between sulfate and sulfide observed here $\left(\sim 5 \%{ }_{0}-55 \%\right)$ encompass the range of bulk fractionations $\left(\sim 36 \%{ }_{0}-42 \%\right)$ reported previously in hypersaline microbial mats (Habicht and Canfield, 1996). There is considerable overlap between our values and the values typically attributed to bacterial-sulfate reduction based on experiments with cultured organisms $(4 \% 0-46 \%)$ (Canfield, 2001 and references therein). This large range reflects the many factors that affect isotopic fractionation during sulfate reduction, including sulfate-reduction rates, type of electron donor and carbon source, incomplete or complete oxidation of organic substrates, temperature and species-specific effects (Jorgensen, 1994; Habicht and Canfield, 1996; Habicht et al., 1998; Canfield, 2001; Porter et al., 2007).

To date, however, bacterial-sulfate reduction has not been shown capable of generating fractionations as large as some of these observed in this study, although theoretical studies (Brunner and Bernasconi, 2005) and pore water data (Wortmann et al.,
2001) suggest it may be possible. The canonical interpretation for fractionations greater than $46 \%$ is the presence of sulfur disproportionation, whereby intermediate valence sulfur species (for example, $S^{0}$, $\mathrm{S}_{2} \mathrm{O}_{3}$ ) are converted into sulfate and sulfide, resulting in increased isotopic fractionation between cooccurring sulfate and sulfide (Canfield, 2001). The nanoSIMS isotopic data presented here suggest the presence and localized metabolic activity of disproportionators distributed within these mat environments. Sulfur cycling is mediated through diverse microorganisms and metabolisms that can affect both the concentration and isotopic composition of sulfur species, including sulfate reducers, sulfur disproportionators and chemolithotrophic and phototrophic sulfide oxidizers-all of which are likely to exist in the mats at Guerrero Negro (for example, Ley et al., 2006). Ongoing work is aimed at extending the CARD-FISH analyses to include different sulfate-reducing populations as well as examining the spatial relationships and abundance of these different sulfur-cycling metabolic guilds within the mats.

\section{Conclusions}

We have adapted the silver-plating strategy previously used for sulfate-reduction rate measurements (for example, Visscher et al., 2000) to capture sulfide from microbial mats and analyze its abundance and isotopic $\left(\delta^{34} S\right)$ composition across the oxycline using nanoSIMS. Captured sulfide records $2 \mathrm{D}$ variability in the abundance and isotopic composition of pore water hydrogen sulfide and offers key advantages over conventional measurements for studying sulfate reduction across steep oxic/anoxic transition zones (Wieland et al., 2005). We observe fine-scale $(1-400 \mu \mathrm{m})$ laminations and localized zonation in sulfide abundance and isotopic composition with fractionations as high as $55 \%$, suggestive of active sulfur disproportionation. CARD-FISH revealed both spatially coherent (that is, laminated or aggregated) and disseminated sulfate reducers at depth throughout the microbial mats. Together, these data point toward spatially variable microbial metabolic activity generating micron-scale variations in both sulfide concentration and its isotopic composition throughout the mats. This paired high-resolution study describes 2D micron-scale variation in both geochemistry and microbial populations, providing an essential link between active microbial activity and the resulting isotopic signatures at a scale relevant to the microorganisms.

\section{Acknowledgements}

We would like to acknowledge the Gordon and Betty Moore Foundation and the Caltech Center for Geochemical 
and Cosmochemical Microanalysis for funding (to VJO) as well as support from National Aeronautics and Space Administration Grant NAI02-003-0001 issued through the Astrobiology Program. DAF was supported by the Caltech OK Earl Postdoctoral Fellowship. CLG was supported by a National Science Foundation Graduate Research Fellowship. We would like to thank Yunbin Guan, John Eiler and Tina Treude for analytical assistance and invaluable discussions, Bill Ussler for discussions and assistance with methodological development, Frank Stadermann for discussions and Dirk de Beer for a critical reading of this manuscript. We are also indebted to the NASA Ames group (Tori Hoehler, Niko Finke, Kendra Turk, Mike Kubo, Linda Jahnke and David DesMarais) for support and assistance with sample collections.

\section{References}

Anbar AD, Knoll AH. (2002). Proterozoic ocean chemistry and evolution: a bioinorganic bridge? Science 297: 1137-1142.

Baumgartner LK, Reid RP, Dupraz C, Decho AW, Buckley DH, Spear JR et al. (2006). Sulfate reducing bacteria in microbial mats: changing paradigms, new discoveries. Sediment Geol 185: 131-145.

Brunner B, Bernasconi SM. (2005). A revised isotope fractionation model for dissimilatory sulfate reduction in sulfate reducing bacteria. Geochimica et Cosmochimica Acta 69: 4759-4771.

Canfield DE. (2001). Biogeochemistry of sulfur isotopes. Rev Mineral Geochem 43: 607-636.

Canfield DE, Des Marais DJ. (1993). Biogeochemical cycles of carbon, sulfur, and free oxygen in a microbial mat. Geochimica Et Cosmochimica Acta 57: 3971-3984.

Canfield DE, Teske A. (1996). Late Proterozoic rise in atmospheric oxygen concentration inferred from phylogenetic and sulphur-isotope studies. Nature 382: 127-132.

Cline JD. (1969). Spectrophotometric determination of hydrogen sulfide in natural waters. Limnol Oceanogr 14: 454-458.

Clode PL, Stern RA, Marshall AT. (2007). Subcellular imaging of isotopically labeled carbon compounds in a biological sample by ion microprobe (NanoSIMS). Microsc Res Tech 70: 220-229.

Cypionka H. (2000). Oxygen respiration by Desulfovibrio species. Annu Rev Microbiol 54: 827-848.

Decho AW, Visscher PT, Reid RP. (2005). Changes in microspatial organization of bacteria during development of surface microbial mats of marine lithifying stromatolites determined using combined FISH/ GIS-image analyses. Geophys Res Abstr 7: 07807.

Decker KLM, Potter CS, Bebout BM, Des Marais DJ, Carpenter S, Discipulo M et al. (2005). Mathematical simulation of the diel O, S, and C biogeochemistry of a hypersaline microbial mat. Fems Microbiol Ecol 52: 377-395.

Des Marais DJ, Cohen Y, Nguyen H, Cheatham M, Cheatham T, Munos E. (1989). Carbon isotopic trends in the hypersaline ponds and microbial mats at Guerrero Negro, Baja California Sur, Mexico: implications for precambrian stromatolites. In: Cohen Y, Rosenberg E. (eds). Microbial Mats: Physiological Ecology of Benthic Microbial Communities. American
Society for Microbiology: Washington, DC, pp 191-203.

Dupraz C, Visscher PT, Baumgartner LK, Reid RP. (2004). Microbe-mineral interactions: early carbonate precipitation in a hypersaline lake (Eleuthera Island, Bahamas). Sedimentology 51: 745-765.

Fike DA, Grotzinger JP, Pratt LM, Summons RE. (2006). Oxidation of the Ediacaran ocean. Nature 444: 744-747.

Frund C, Cohen Y. (1992). Diurnal cycles of sulfate reduction under oxic conditions in cyanobacterial mats. Appl Environ Microbiol 58: 70-77.

Gill BC, Lyons TW, Saltzman MR. (2007). Parallel, highresolution carbon and sulfur isotope records of the evolving Paleozoic marine sulfur reservoir. Palaeogeogr Palaeoclimatol Palaeoecol 256: 156-173.

Grotzinger JP, Knoll AH. (1999). Stromatolites in precambrian carbonates: evolutionary mileposts or environmental dipsticks? Annu Rev Earth Planet Sci 27: 313-358.

Habicht KS, Canfield DE. (1996). Sulphur isotope fractionation in modern microbial mats and the evolution of the sulphur cycle. Nature 382: 342-343.

Habicht KS, Canfield DE, Rethmeier J. (1998). Sulfur isotope fractionation during bacterial reduction and disproportionation of thiosulfate and sulfite. Geochimica Et Cosmochimica Acta 62: 2585-2595.

Habicht KS, Gade M, Thamdrup B, Berg P, Canfield DE. (2002). Calibration of sulfate levels in the Archean ocean. Science 298: 2372-2374.

Hayes JM, Waldbauer JR. (2006). The carbon cycle and associated redox processes through time. Philos Trans $R$ Soc Lond B Biol Sci 361: 931-950.

Hoehler TM, Bebout BM, Des Marais DJ. (2001). The role of microbial mats in the production of reduced gases on the early Earth. Nature 412: 324-327.

Hoppe P, Mostefaoui S, Stephan T. (2005). O- and S-isotope imaging of primitive solar system materials with the Mainz NanoSIMS. Geochimica Et Cosmochimica Acta 69: A523.

Hurtgen MT, Arthur MA, Halverson GP. (2005). Neoproterozoic sulfur isotopes, the evolution of microbial sulfur species, and the burial efficiency of sulfide as sedimentary pyrite. Geology 33: 41-44.

Jeroschewsky P, Steuckart C, Kuehl M. (1996). An amperometric microsensor for the determination of $\mathrm{H}_{2} \mathrm{~S}$ in aquatic environments. Anal Chem 68: 4351-4357.

Jorgensen BB. (1994). Sulfate reduction and thiosulfate transformations in a cyanobacterial mat during a diel oxygen cycle. FEMS Microbiol Ecol 13: 303-312.

Jorgensen BB, Revsbech NP, Blackburn TH, Cohen Y. (1979). Diurnal cycle of oxygen and sulfide microgradients and microbial photosynthesis in a cyanobacterial mat sediment. Appl Environ Microbiol 38: 46-58.

Kampschulte A, Strauss H. (2004). The sulfur isotopic evolution of Phanerozoic seawater based on the analysis of structurally substituted sulfate in carbonates. Chem Geol 204: 255-286.

Krekeler D, Sigalevich P, Teske A, Cypionka H, Cohen Y. (1997). A sulfate-reducing bacterium from the oxic layer of a microbial mat from Solar Lake (Sinai), Desulfovibriooxyclinae sp. nov. Arch Microbiol 167: 369-375.

Kuehl M, Steuckart C, Eickert G, Jeroschewsky P. (1998). A $\mathrm{H}_{2} \mathrm{~S}$ microsensor for profiling biofilms and 
sediments: application in an acidic lake sediment. Aquat Microb Ecol 15: 201-209.

Ley RE, Harris JK, Wilcox J, Spear JR, Miller SR, Bebout $\mathrm{BM}$ et al. (2006). Unexpected diversity and complexity of the Guerrero Negro hypersaline microbial mat. Appl Environ Microbiol 72: 3685-3695.

Li T, Wu TD, Mazeas L, Toffin L, Guerquin-Kern JL, Leblon $\mathrm{G}$ et al. (2008). Simultaneous analysis of microbial identity and function using NanoSIMS. Environ Microbiol 10: 580-588.

Loy A, Maixner F, Wagner M, Horn M. (2007). ProbeBasean online resource for rRNA-targeted oligonucleotide probes: new features 2007. Nucleic Acids Res 35: D800-D804.

Manz W, Eisernbrecher M, Neu TR, Szewzyk U. (1998). Abundance and spatial organization of Gram-negative sulfate-reducing bacteria in activated sludge investigated by in situ probing with specific 16S rRNA targeted oligonucleotides. FEMS Microbiol Ecol 25: 43-61.

Minz D, Fishbain S, Green SJ, Muyzer G, Cohen Y, Rittmann BE et al. (1999a). Unexpected population distribution in a microbial mat community: sulfatereducing bacteria localized to the highly oxic chemocline in contrast to a eukaryotic preference for anoxia. Appl Environ Microbiol 65: 4659-4665.

Minz D, Flax JL, Green SJ, Muyzer G, Cohen Y, Wagner M et al. (1999b). Diversity of sulfate-reducing bacteria in oxic, anoxic regions of a microbial mat characterized by comparative analysis of dissimilatory sulfite reductase genes. Appl Environ Microbiol 65: 4666-4671.

Musselwhite CL, Swift D, Gilpen J, McInerney MJ. (2007). Spatial variability of sulfate reduction in a shallow aquifer. Environ Microbiol 9: 2810-2819.

Pernthaler A, Pernthaler J, Amann R. (2002). Fluorescence in situ hybridization and catalyzed reporter deposition for the identification of marine bacteria. Appl Environ Microbiol 68: 3094-3101.

Pernthaler A, Pernthaler J, Amann R. (2004). Molecular Microbial Ecology Manual. Kluwer Academic Press: Dordrecht, The Netherlands.

Porter D, Roychoudhury AN, Cowan D. (2007). Dissimilatory sulfate reduction in hypersaline coasal pans: activity across a salinity gradient. Geochimica Et Cosmochimica Acta 71: 5102-5116.

Revsbech NP. (1989). An oxygen sensor with a guard cathode. Limnol Oceanogr 34: 474-478.

Revsbech NP, Jorgensen BB, Blackburn TH, Cohen Y. (1983). Microelectrode studies of the photosynthesis and $\mathrm{O} 2, \mathrm{H} 2 \mathrm{~S}$, and $\mathrm{pH}$ profiles of a microbial mat. Limnol Oceanogr 28: 1062-1074.

Risatti JB, Capman WC, Stahl DA. (1994). Community structure of a microbial mat: the phylogenetic dimension. Proc Natl Acad Sci USA 91: 10173-10177.

Sigalevich P, Baev MV, Teske A, Cohen Y. (2000). Sulfate reduction and possible aerobic metabolism of the sulfate-reducing bacterium Desulfovibrio oxyclinae in a chemostat coculture with Marinobacter sp strain MB under exposure to increasing oxygen concentrations. Appl Environ Microbiol 66: 5005-5012.

Slodzian G, Hillion F, Stadermann FJ, Zinner E. (2004). QSA influences on isotopic ratio measurements. Appl Surf Sci 231-2: 874-877.

Sorensen KB, Canfield DE, Teske AP, Oren A. (2005). Community composition of a hypersaline endoevaporitic microbial mat. Appl Environ Microbiol 71: $7352-7365$.

Spear JR, Ley RE, Berger AB, Pace NR. (2003). Complexity in natural microbial ecosystems: the Guerrero Negro experience. Biol Bull 204: 168-173.

Steedman HF. (1957). Polyester wax: a new ribboning embedding medium for histology. Nature 179: 1345.

Studley SA, Ripley EM, Elswick ER, Dorais MJ, Fong J, Finkelstein D et al. (2002). Analysis of sulfides in whole rock matrices by elemental analyzer-continuous flow isotope ratio mass spectrometry. Chem Geol 192: 141-148.

Teske A, Ramsing NB, Habicht K, Fukui M, Kuver J, Jorgensen BB et al. (1998). Sulfate-reducing bacteria and their activities in cyanobacterial mats of Solar Lake (Sinai, Egypt). Appl Environ Microbiol 64: 29432951.

Tonolla M, Peduzzi R, Hahn D. (2005). Long-term population dynamics of phototrophic sulfur bacteria in the chemocline of Lake Cadagno, Switzerland. Appl Environ Microbiol 71: 3544-3550.

Visscher PT, Baumgartner LK, Buckley DH, Rogers DR, Hogan ME, Raleigh CD et al. (2003). Dimethyl sulphide and methanethiol formation in microbial mats: potential pathways for biogenic signatures. Environ Microbiol 5: 296-308.

Visscher PT, Reid RP, Bebout BM. (2000). Microscale observations of sulfate reduction: Correlation of microbial activity with lithified micritic laminae in modern marine stromatolites. Geology 28: 919-922.

Wieland A, de Beer D, Damgaard LR, Kuehl M, van Dusschoten D, Van As H. (2001). Fine-scale measurement of diffusivity in a microbial mat with nuclear magnetic resonance imaging. Limnol Oceanogr 46: 248-259.

Wieland A, Kuehl M, McGowan L, Sole A, Diestra E, Esteve I et al. (2003). Microbial mats on the Orkney Islands revisited: microenvironment and microbial community composition. Microb Ecol 46: 371-390.

Wieland A, Zopfi J, Benthien A, Kuhl M. (2005). Biogeochemistry of an iron-rich hypersaline microbial mat (Camargue, France). Microb Ecol 49: 34-49.

Wieringa EBA, Overmann J, Cypionka H. (2000). Detection of abundant sulphate-reducing bacteria in marine oxic sediment layers by a combined cultivation and molecular approach. Environ Microbiol 2: 417-427.

Wortmann UG, Bernasconi SM, Boettcher ME. (2001). Hypersulfidic deep biosphere indicates extreme sulfur isotope fractionation during single step microbial sulfate reduction. Geology 29: 647-650.

Supplementary Information accompanies the paper on The ISME Journal website (http://www.nature.com/ismej) 